\title{
Review \\ A Comparison of Methods for the Production of Kilobase-Length Single-Stranded DNA
}

\author{
Chang-Yong $\mathrm{Oh}^{1, *}$ and Eric R. Henderson ${ }^{2}$
}

1 Department of Biochemistry, Biophysics, and Molecular Biology, Iowa State University, Ames, IA 50011, USA

2 Department of Genetics, Development, and Cell Biology, Iowa State University, Ames, IA 50011, USA; telomere@iastate.edu

* Correspondence: johnoh@iastate.edu

check for updates

Citation: Oh, C.-Y.; Henderson, E.R A Comparison of Methods for the Production of Kilobase-Length Single-Stranded DNA. DNA 2022, 2, 56-67. https://doi.org/10.3390/ dna2010005

Academic Editors: Maria C. DeRosa and Ashis Basu

Received: 3 January 2022

Accepted: 18 February 2022

Published: 1 March 2022

Publisher's Note: MDPI stays neutral with regard to jurisdictional claims in published maps and institutional affiliations.

Copyright: (C) 2022 by the authors. Licensee MDPI, Basel, Switzerland. This article is an open access article distributed under the terms and conditions of the Creative Commons Attribution (CC BY) license (https:// creativecommons.org/licenses/by/ $4.0 /)$.

\begin{abstract}
DNA nanoengineering, in particular, DNA origami has potential applications in a variety of areas including, for example, nanoelectronics, biomedical diagnostics, and therapeutics. To fully realize the potential of DNA self-assembly in these and other areas, methods must be available for economical, scalable, and reliable production of single-stranded DNA (ssDNA) scaffolds from virtually any source. In this review, we will describe the virtues and liabilities of four strategies for generating ssDNA, including Rolling Circle Amplification (RCA), strand-specific exonuclease digestion, chemical denaturation, and asymmetric PCR (aPCR), with suggestions for approaches to optimize the use of each method.
\end{abstract}

Keywords: DNA nanoengineering; DNA origami; scaffold; rolling circle amplification; lambda exonuclease; chemical denaturation; asymmetric polymerase chain reaction

\section{Introduction}

Nanoengineering by virtue of DNA-based self-assembly [1-5] is emerging as a platform methodology for addressing a variety of interesting issues ranging from nanoelectronics to biomedical diagnostics and therapeutics [5-10]. In many (but not all) of these methods, a single-stranded nucleic acid "scaffold" is required, and this role is often played by the natural single-stranded DNA (ssDNA) scaffold of the bacteriophage M13, predominately because of its accessibility $[3,11]$. Although the use of the M13 scaffold has led to a vast number of advances, it significantly constrains the realization of the full potential of the DNA self-assembly platform. Thus, to fully leverage the inherent utility of DNA nanoengineering it must be possible to create ssDNA scaffolds easily and reliably from essentially any source [11-13]. In this report, we describe the virtues and liabilities of four relatively economical and simple approaches for producing long ssDNA molecules. These methods are 1, Rolling Circle Amplification (RCA), 2, strand-specific exonuclease digestion, 3 , chemical denaturation, and, 4, asymmetric polymerase chain reaction (aPCR).

\subsection{Rolling Circle Amplification (RCA)}

Rolling Circle Amplification (RCA) is a very efficient method for generating large quantities of ssDNA in a simple isothermal reaction [11,14-16]. Standard RCA employs phi29 DNA polymerase because of its high processivity and strong strand displacement ability $[11,14,17]$. As such, this method is capable of producing long concatemers of the desired DNA sequence [11,16,17]. Further, this approach can be scaled to industrial levels [16]. However, standard RCA carried out using phi29 polymerase has the intrinsic problem of producing terminal double-stranded DNA (dsDNA) byproducts by consuming ssDNA products in what has been described as a "strand jumping" event. To mitigate this situation, single-strand binding protein (SSB) can be included in the RCA reaction, but at additional cost and creating a need for additional post-synthesis purification steps [17]. Also, the reaction requires a circular template, nicked on the desired strand, which can be problematic 
in some instances [18] since the substrate for the reaction must contain one or more sites amenable to nicking by a relatively small pool of sequence-specific nicking endonucleases ("nickases") [16,17]. Finally, cleavage of concatemeric RCA products into monomeric ssDNA is critical for the utilization of products for downstream applications [19]. Thus, for the efficient production of large quantities of ssDNA at a low cost, RCA is only applicable in a subset of cases in which these favorable conditions exist.

\subsection{Strand-Specific Lambda Exonuclease Digestion}

Lambda exonuclease preferentially digests dsDNA from the $5^{\prime}$-phosphorylated end. This feature can be leveraged to create ssDNA by asymmetrically phosphorylating the $5^{\prime}$ end of a dsDNA template, generally prepared by PCR [11,20-22]. It is noteworthy that lambda exonuclease is also capable of digesting the non-phosphorylated $5^{\prime}-\mathrm{OH}$ strand, but at a lower, albeit, not insignificant rate [21,22]. Thus, the enzyme concentration and incubation time must be carefully optimized to produce predominantly full-length desired strand [21,22]. A useful modification of this method to rectify this inherent problem is to asymmetrically modify the $5^{\prime}$ termini to protect the desired strand in concert with the $5^{\prime}$ phosphorylation of the undesired strand. Protective modifications include, for example, the addition of $5^{\prime}$ inverted $\mathrm{dT}$, the inclusion of terminal phosphorothioate bonds, and $5^{\prime}$ biotinylation [22,23]. Terminal base modifications have to be chosen carefully based on downstream applications since they have the potential to impact the behavior of the resultant modified ssDNA. Phosphorothioate modification has been reported to be relatively innocuous in this respect $[23,24]$. Coupled with chemical protection of the $5^{\prime}$ terminus of the desired strand, strand-specific lambda exonuclease digestion offers the benefits of rapid production and optimization [20-22]. Despite the simplicity and rapid production, the strand-specific lambda degradation method may be sub-optimal for large-scale production of ssDNA. Incomplete degradation of dsDNA contributes to low production yield and the purification steps required for removal of enzyme often result in further loss of ssDNA [11,21]. In some cases, these drawbacks can be alleviated by coupling this approach with well-optimized conventional PCR and ensuring complete $5^{\prime}$ phosphorylation of the target strand [22].

\subsection{Chemical Denaturation}

Chemicals such as urea, formamide, and sodium hydroxide $(\mathrm{NaOH})$ can be used to denature the DNA double helix via hydrogen bond disruption [21,25-29]. Identification and isolation of the desired strand post-denaturation can be accomplished by, for example, asymmetric biotin modification using a variety of streptavidin (or avidin) selection systems [21,25,26] or agarose gel electrophoresis (AGE) [24,26,27]. $\mathrm{NaOH}$ and urea are the most commonly used chemical denaturants based on their high efficiency, and economy $[21,27,28,30,31]$. However, these methods can be somewhat dangerous, and extensive purification may be required to remove residual denaturants $[21,26,28]$. Further, when coupled with biotin-streptavidin selection systems, the $\mathrm{NaOH}$ concentration has to be carefully chosen to obtain the maximum desired product yield [30]. Thus, we have developed a simpler method wherein the dsDNA is briefly heated in a 50\% formamide solution [25,29] and rapidly loaded on a native agarose gel, thereby minimizing the re-hybridization of the two strands. It is advantageous to nick the undesired strand with a commercially available nicking endonuclease to reduce the probability that the two ssDNA strands will co-migrate and thereby preclude facile isolation of the desired strand [27]. Following denaturation and electrophoretic strand separation, the desired strand must be removed from the gel which, with existing commercial methods, can reduce yield. 


\subsection{Asymmetric PCR (aPCR)}

Asymmetric PCR (aPCR) is one of the simplest methods for generating ssDNA from a dsDNA template, the latter usually generated by standard PCR [11]. aPCR produces an asymmetric distribution of the two strands by using unequal concentrations of forward and reverse primers, one of which is present, by choice, in a limiting concentration. Initially, dsDNA is produced but once the limiting primer is consumed there is a shift to linear (non-logarithmic) production of the desired ssDNA by the primer that is present in excess $[11,32,33]$. Despite its apparent simplicity, aPCR can be fraught with sequence-based limitations (e.g., primer site duplicity, excessive length, byproduct formation by ssDNA product dimerization). Thus, careful optimization is required for each template and in some cases, a satisfactory parameter set cannot be readily established [33]. Methods have been developed to help alleviate this problem. For example, Veneziano et al. compared a wide range of commercially available thermally stable DNA polymerases and identified several that demonstrate superior ability to produce large-scale ssDNA by aPCR [32].

\section{Materials and Methods}

\subsection{Rolling Circle Amplification}

\subsubsection{Preparation of Nicked Template for RCA}

Nt.BspQI was purchased from New England Biolabs (NEB, Ipswich, MA, USA), and pUC19 was purchased from Bayou Biolabs (Metairie, LA, USA). The nicking reaction mixture was carried out in $50 \mu \mathrm{L}$ volumes containing $1 \times$ NEB buffer $\mathrm{r} 3.1(100 \mathrm{mM} \mathrm{NaCl}$, $50 \mathrm{mM}$ Tris- $\mathrm{HCl}, 10 \mathrm{mM} \mathrm{MgCl} 2,100 \mu \mathrm{g} / \mathrm{mL}$ recombinant albumin, $\mathrm{pH} 7.9$ at $\left.25^{\circ} \mathrm{C}\right), 1 \mu \mathrm{L}$ Nt.BspQI, $1 \mu \mathrm{g}$ pUC19, and nuclease-free water to bring the volume up to $50 \mu \mathrm{L}$. The sample was incubated at $50{ }^{\circ} \mathrm{C}$ for $1 \mathrm{~h}$. and heat-inactivated at $80{ }^{\circ} \mathrm{C}$ for $20 \mathrm{~min}$. The reaction product was mixed with NEB $6 \times$ loading dye (containing $15 \%$ Ficoll $^{\circledR}-400,60 \mathrm{mM}$ EDTA, $19.8 \mathrm{mM}$ Tris- $\mathrm{HCl}, 0.48 \%$ SDS, $0.12 \%$ Dye $1,0.006 \%$ Dye 2 , $\mathrm{pH} 8$ at $25^{\circ} \mathrm{C}$ ) and then loaded onto a $1 \%$ agarose gel pre-stained with SYBR Safe DNA dye (Invitrogen, Waltham, MA, USA). Electrophoresis was carried out at $8 \mathrm{~V} / \mathrm{cm}$ for $1 \mathrm{~h}$. The SYBR Safe-stained DNA was visualized using a $490 \mathrm{~nm}$ wavelength (blue) transilluminator and an amber filter.

\subsubsection{RCA Mediated ssDNA Production}

Phi29 polymerase and reaction materials were purchased from NEB. RCA reactions were carried out in $50 \mu \mathrm{L}$ volumes containing $1 \times$ phi2 2 buffer $(50 \mathrm{mM}$ Tris- $\mathrm{HCl}, 10 \mathrm{mM}$ $\mathrm{MgCl}_{2}, 10 \mathrm{mM}\left(\mathrm{NH}_{4}\right)_{2} \mathrm{SO}_{4}, 4 \mathrm{mM}$ DTT, pH 7.5 at $25{ }^{\circ} \mathrm{C}$ ), 30 ng nicked pUC19 (prepared as above), $1 \mathrm{mM}$ dNTP mix, $200 \mathrm{ng} / \mathrm{uL}$ BSA from, $1 \mu \mathrm{L}$ phi29 polymerase, $\pm 200 \mathrm{ng} / \mu \mathrm{L}$ T4 Gene 32 SSB, and nuclease-free water to bring the volume up to $50 \mu \mathrm{L}$. The reactions were carried out at $30{ }^{\circ} \mathrm{C}$ for $24 \mathrm{~h}$. The products were loaded onto a $1 \%$ agarose gel and electrophoresed as above. The gel was post-stained with $1 \times$ SYBR Gold from Thermofisher (Waltham, MA, USA) and visualized as above.

\subsubsection{Digestion of RCA Products-XmnI Was Purchased from NEB}

The digestion reaction mixtures were carried out in $50 \mu \mathrm{L}$ volumes containing $1 \times$ CutSmart buffer $(50 \mathrm{mM}$ potassium acetate, $20 \mathrm{mM}$ Tris-acetate, $10 \mathrm{mM}$ magnesium acetate, $100 \mu \mathrm{g} / \mathrm{mL}$ BSA, $\mathrm{pH} 7.9$ at $\left.25^{\circ} \mathrm{C}\right), 1 \mu \mathrm{L} \mathrm{XmnI}, 10 \mu \mathrm{L}$ RCA ( \pm SSB) products, and nuclease-free water to bring the volume up to $50 \mu \mathrm{L}$. The reactions were carried out at $37^{\circ} \mathrm{C}$ for $1 \mathrm{~h}$ and heat-inactivated at $65^{\circ} \mathrm{C}$ for $20 \mathrm{~min}$. The reaction products were loaded onto a $1 \%$ agarose gel cast pre-stained with $1 \times$ SYBR Safe, electrophoresed, and visualized as above. 


\subsection{Strand-Specific Lambda Exonuclease Degradation}

Lambda exonuclease was purchased from NEB. Each lambda digestion reaction was carried out in $50 \mu \mathrm{L}$, composed of $1 \times$ NEB lambda exonuclease buffer ( $67 \mathrm{mM}$ Glycine$\mathrm{KOH}, 2.5 \mathrm{mM} \mathrm{MgCl} 2,50 \mu \mathrm{g} / \mathrm{mL} \mathrm{BSA}$, pH 9.4 at $\left.25^{\circ} \mathrm{C}\right), 1 \mu \mathrm{g}$ double-stranded Green Fluorescent Protein (dsGFP) (generated by standard PCR, purified as described below; Supplementary Materials), $2 \mu \mathrm{L}$ lambda exonuclease, and nuclease-free water to final volume. The mixtures were incubated at $37^{\circ} \mathrm{C}$ for $30,60,120$, and $240 \mathrm{~min}$ respectively, and heat-inactivated at $75^{\circ} \mathrm{C}$ for $10 \mathrm{~min}$. Each product was mixed with $10 \mu \mathrm{L} 6 \times$ loading dye from NEB and loaded onto $1 \%$ agarose gel pre-stained with $1 \times$ SYBR Safe. The gel was electrophoresed and visualized as above.

\subsection{Formamide Separation}

Nt.BsmAI (NEB) was used to nick the undesired strand. The nicking reaction was composed of $1 \times$ CutSmart buffer ( $50 \mathrm{mM}$ potassium acetate, $20 \mathrm{mM}$ Tris-acetate, $10 \mathrm{mM}$ magnesium acetate, $100 \mu \mathrm{g} / \mathrm{mL}$ BSA, pH 7.9 at $25^{\circ} \mathrm{C}$ ) (NEB), $2 \mu \mathrm{L}$ Nt.BsmAI, $2 \mu \mathrm{g}$ of dsGFP (generated from standard PCR, purified as described below; Supplementary Materials), and nuclease-free water to bring the volume up to $50 \mu \mathrm{L}$. The mixture was incubated at $37^{\circ} \mathrm{C}$ for $2 \mathrm{~h}$ and heat-inactivated at $75^{\circ} \mathrm{C}$ for $10 \mathrm{~min}$. The product was mixed with $10 \mu \mathrm{L}$ $6 \times$ loading dye (NEB) and then loaded onto $1 \%$ agarose gel pre-stained with $1 \times$ SYBR Safe. The sample was electrophoresed and visualized as above. $1 \mu \mathrm{g}$ of gel-purified nicked dsGFP was mixed with an equal volume of $2 \times$ gel loading dye II (95\% formamide; Thermofisher). The mixture was heated to $80^{\circ} \mathrm{C}$ for $10 \mathrm{~min}$ for strand separation. For isolation of separated strands, the heated mixture was quickly loaded onto a native $1 \%$ agarose gel pre-stained with $1 \times$ SYBR Safe. The gel was electrophoresed and visualized as above.

\subsection{Asymmetric PCR (aPCR)}

Primers for amplification of the Green Fluorescent Protein (GFP) gene were designed using Snapgene and purchased from Integrated DNA Technologies (IDT). Sequences of each primer are listed in Table 1. Each aPCR reaction was carried out in $50 \mu \mathrm{L}$ total volume, composed of $1 \times \mathrm{HiFi}$ PCR buffer ( $60 \mathrm{mM}$ Tris-SO ${ }_{4}, 18 \mathrm{mM}\left(\mathrm{NH}_{4}\right)_{2} \mathrm{SO}_{4}, \mathrm{pH}$ 8.9) from Promega, $2 \mathrm{mM} \mathrm{MgSO}_{4}$ (Promega, Madison, WI, USA), $1 \mathrm{uM}$ antisense primer (GFP exoanti $=$ desired), $20 \mathrm{nM}$ sense primer (GFP exo-sense $=$ undesired), $200 \mathrm{nM}$ dNTP mix from $\mathrm{NEB}, 13.7 \mathrm{ng} / \mathrm{uL}$ dsGFP (generated by standard PCR; Supplementary Materials), $0.2 \mu \mathrm{L}$ Accustart Taq DNA polymerase HiFi (Promega), and nuclease-free water to final volume. Each aPCR was performed using the following thermocycler steps: $30 \mathrm{~s}$ at $94{ }^{\circ} \mathrm{C}, 30 \mathrm{~s}$ at $59^{\circ} \mathrm{C}$, and 2 min at $68^{\circ} \mathrm{C}$ for 25 cycles. Each $50 \mu \mathrm{L}$ aPCR product was mixed with $10 \mu \mathrm{L}$ $6 \times$ loading dye from NEB and loaded onto $1 \%$ agarose cast pre-stained with $1 \times$ SYBR Safe and electrophoresed and visualized as above.

Table 1. Sequences of primers used in standard PCR and aPCR.

\begin{tabular}{|c|c|}
\hline Primer Name & Sequences \\
\hline $\begin{array}{l}\text { GFP exo-sense } \\
\text { (undesired strand) }\end{array}$ & 5'-/5Phos/ATT AGT TCA TAG CCC ATA TAT GGA GTT CCG-3' \\
\hline $\begin{array}{l}\text { GFP exo-anti } \\
\text { (desired strand) }\end{array}$ & $\begin{array}{l}5^{\prime}-\mathrm{T} * \mathrm{~A} * \mathrm{~T} * \mathrm{~A} * \mathrm{~T} * \mathrm{~A} \text { TAC GCC TTA AGA TAC ATT GAT GAG TTT } \\
\text { GGA C-3 }\end{array}$ \\
\hline
\end{tabular}

/5Phos/: $5^{\prime}$ phosphorylated; *: phosphorothioated DNA bases; GFP: Green Fluorescent Protein

\subsection{DNA Purification}

\subsection{1. dsDNA Purification}

A Zymoclean Gel DNA Recovery Kit (Zymo Research, Irvine, CA, USA) was used to extract dsDNA from agarose gels. Gel bands containing target dsDNA were sliced and removed using a clean razor blade. Three volumes of the provided agarose dissolving/binding buffer were added to each sliced gel fragment and incubated at $55{ }^{\circ} \mathrm{C}$ on a 
heating block for $15 \mathrm{~min}$. Each dissolved gel solution was transferred to the provided silica-based spin columns and centrifuged at 10,000 rcf (relative centrifugal force) for $60 \mathrm{~s}$ in a table-top centrifuge. $200 \mu \mathrm{L}$ of ethanol-based DNA wash buffer was added to each spin column and centrifuged at 10,000 $\mathrm{rcf}$ for $30 \mathrm{~s}$. A washing step was repeated before centrifuging at 10,000 rcf for $60 \mathrm{~s}$ for complete removal of ethanol. Flow-through from all steps was discarded. After transferring each spin column to a clean microcentrifuge tube, 6-20 $\mu \mathrm{L}$ of the provided elution buffer was added directly to the matrix of each spin column followed by centrifugation at 10,000 rcf for $60 \mathrm{~s}$ for DNA collection. A fraction of each purified dsDNA was mixed with $6 \times$ loading dye loaded onto $1 \%$ agarose gel pre-stained with $1 \times$ SYBR safe. The gel was run at $8 \mathrm{~V} / \mathrm{cm}$ for $1 \mathrm{~h}$. The quantity of the purified dsDNA samples was evaluated by measuring band intensities using GelAnalyzer 19.1 available at www.gelanalyzer.com (accessed on 19 August 2021).

\subsection{2. ssDNA Purification}

A Zymoclean Gel RNA Recovery Kit from Zymo Research was used to purify ssDNA from agarose gels. The gel bands containing target ssDNA were excised with a clean razor blade. Three volumes of the provided agarose dissolving/binding buffer were added to each excised gel band and melted at $55{ }^{\circ} \mathrm{C}$ on a heating block for $15 \mathrm{~min}$. Each dissolved gel solution was transferred to the provided silica-based spin columns and centrifuged at $12,000 \mathrm{rcf}$ for $2 \mathrm{~min}$. $400 \mu \mathrm{L}$ RNA Prep buffer was added to each spin column followed by centrifugation at 12,000 rcf for $1 \mathrm{~min}$. Washing was carried out by the addition of $800 \mu \mathrm{L}$ ethanol-based wash buffer followed by centrifugation at 12,000 rcf for $30 \mathrm{~s}$. After repeating the washing step with $400 \mu \mathrm{L}$ ethanol-based wash buffer, each spin column was centrifuged at 12,000 rcf for $2 \mathrm{~min}$ to remove residual ethanol. Flow-through in all steps was discarded. After transferring each spin column to clean microcentrifuge tubes, $6-20 \mu \mathrm{L}$ of elution buffer was added directly to the column matrix, and the spin columns were centrifuged at $10,000 \mathrm{rcf}$ for $1 \mathrm{~min}$ for retentate collection. A fraction of each purified ssDNA was mixed with $6 \times$ loading dye and evaluated by gel electrophoresis as described earlier. The quantity of the purified ssDNA samples was measured using GelAnalyzer 19.1.

\section{Results}

Figure 1 is a schematic diagram of each of the methods described above. Standard PCR was used to prepare templates for lambda exonuclease, formamide separation, and aPCR (Figure S1). Verification and purification in all cases were carried out by AGE and the use of a commercially available gel recovery kit as described in Materials and Methods. Verification of ssDNA products from each method was carried out by restriction enzyme digestion and SSB treatment (Figures S2-S4).

\subsection{Rolling Circle Amplification (RCA)}

$\mathrm{RCA}$ in the presence and absence of SSB resulted in high molecular weight bands above $10 \mathrm{~kb}$ and material retained in the gel wells. Restriction digestion was used to evaluate RCA products. In the case of RCA without SSB, the high molecular weight band above $10 \mathrm{~kb}$ was fully digested whereas the high molecular weight material in the gel wells remained undigested, suggesting that a significant portion of RCA product in the absence of SSB was dsDNA with some high molecular weight ssDNA also produced. In the presence of SSB, both high molecular weight bands above $10 \mathrm{~kb}$ and in the gel wells were resistant to digestion, indicating that they were predominantly ssDNA (Figure 2a). 


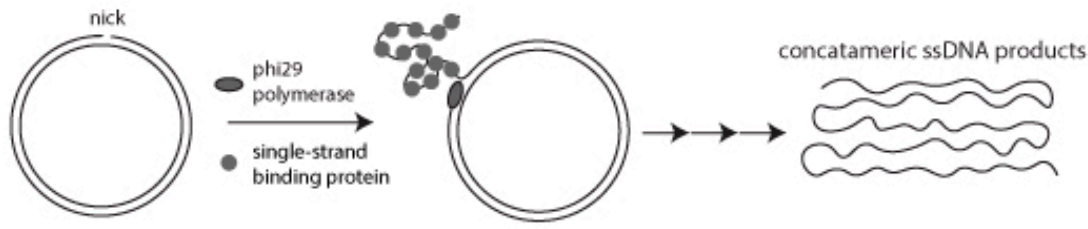

(a)
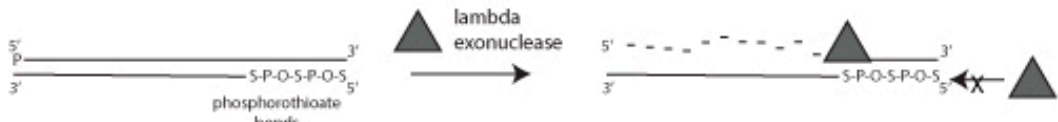

(b)

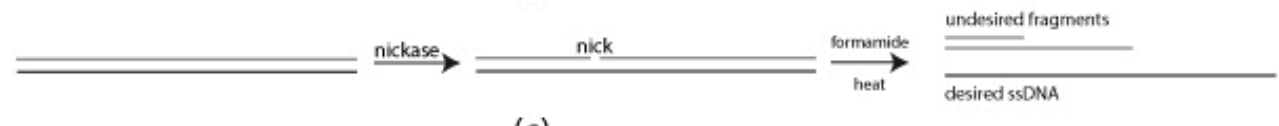

(c)
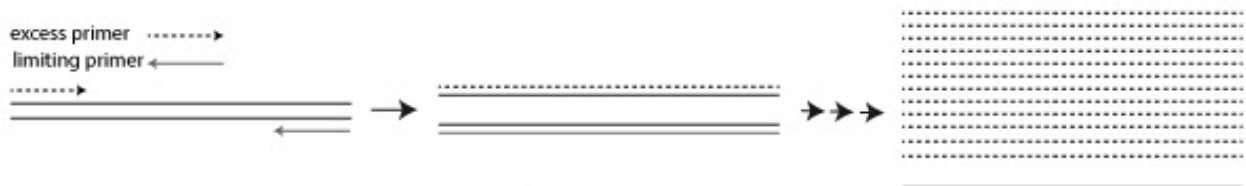

(d)

Figure 1. Schematic diagram of each method for generating single-stranded DNA (ssDNA): (a) Rolling Circle Amplification (RCA) requires single-strand binding protein (SSB) for a progressive generation of single-stranded DNA (ssDNA); (b) Selective digestion of $5^{\prime}$ phosphorylated strand mediated by lambda exonuclease. Phosphorothioate bonds on the desired strand for protection; (c) Formamide-directed strand separation and strand selection through nicking endonuclease treatment and Agarose gel electrophoresis (AGE); (d) Use of unequal concentrations of forward and reverse primers to generate ssDNA.
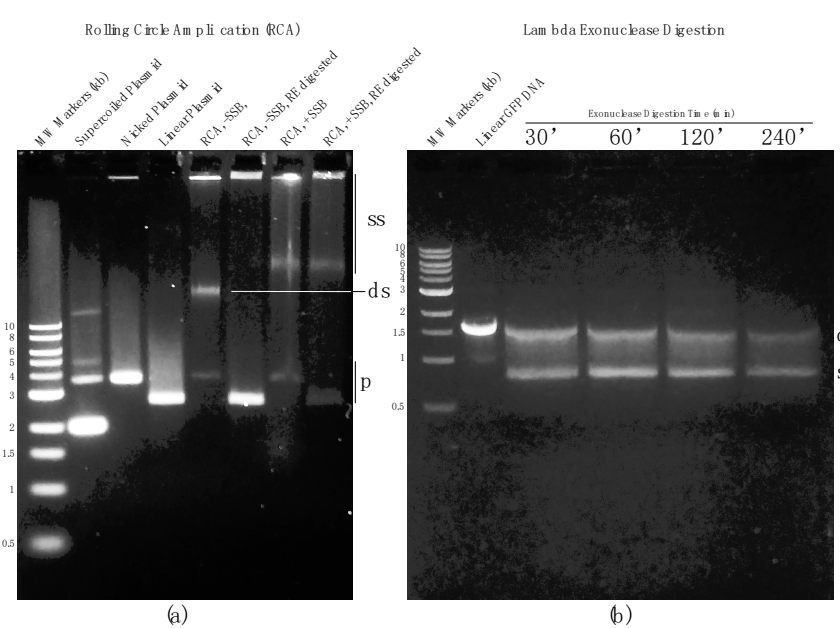

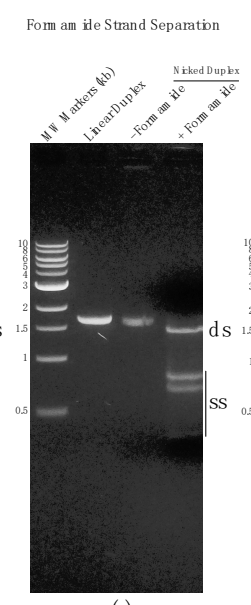

(c)

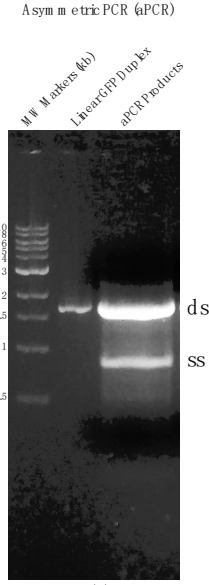

(d)

Figure 2. AGE results from each method described here for generating ssDNA. (a) RCA results in presence or absence of SSB. In the absence of SSB the primary product is double-stranded DNA (dsDNA). (b) Comparison of selective digestion of the $5^{\prime}$ phosphorylated strand of a linear DNA duplex by lambda exonuclease for 30, 60, 120, and $240 \mathrm{~min}$. (c) Formamide-mediated strand separation following nicking endonuclease treatment of a linear DNA duplex. Nicking of the undesired strand greatly improves resolution of the desired strand. (d) Generation of ssDNA by asymmetric PCR (aPCR). SS: ssDNA; DS: dsDNA. 


\subsection{Strand-Specific Lambda Exonuclease Degradation}

Templates for lambda exonuclease-directed degradation were $5^{\prime}$-phosphorylated on the undesired (GFP sense) strand. Conversely, five phosphorothioate linkage modifications on $5^{\prime}$ terminus on the desired (GFP antisense) strand. This arrangement favors selective degradation of the undesired strand. To determine the optimum digestion time for lambdadirected degradation, four reactions were performed for 30, 60, 120, and $240 \mathrm{~min}$ and the results were visualized by AGE. In all four reactions, two bands were observed including one $\sim 1.5 \mathrm{~kb}$ and another $\sim 900 \mathrm{bp}$. Judging from the differences in mobility and staining efficiency, and corroborated by atomic force microscopy (AFM), the band at approximately 900 bp was single-stranded Green Fluorescent Protein DNA (ssGFP). Extending the reaction time led to further digestion of the dsGFP template but also some digestion of the desired ssDNA strand (Figure 2b). Thus, prolonging the reaction time to fully remove the remaining dsDNA fraction was not pursued since it reduced the overall yield of the desired product and potentially compromised its full-length integrity. This method is relatively simple and provides good yield but has the caveats of incomplete processing (in the interest of preserving full-length ssDNA) and subsequent reduction in final product yield due to losses during post agarose gel purification using commercial selective-filter-based systems.

\subsection{Chemical Denaturation}

dsGFP template prepared by conventional PCR was used in chemical denaturation (formamide) studies. The dsGFP was nicked on the undesired strand using the nickase Nt.BsmAI. Nicked products were composed of three different size fragments: a $1676 \mathrm{bp}$ fully intact desired strand, and $1249 \mathrm{bp}$ and $427 \mathrm{bp}$ undesired strand fragments. Nicked dsGFP was purified by AGE followed by gel extraction using a commercially available kit as described in Materials and Methods. Purified nicked products were treated with $2 \times 95 \%$ formamide dye (Thermofisher) and heated to $80^{\circ} \mathrm{C}$ to fully denature the duplex. The single strands were separated by AGE using a native agarose gel with minimal cooling permitted during loading the gel. Each separated fragment was identified based on its mobility on the gel. The AGE results showed that, as expected, a fraction of presumably re-hybridized dsDNA was present. Nonetheless, a substantial fraction remained single-stranded, and the desired strand was clearly separated from the smaller undesired strand fragments. It is noteworthy that isolation of the desired ssDNA strand was challenging in this instance due to the relatively small separation distance between the desired strand and the larger of the two undesired strand fragments (Figure 2c). This can be rectified by a longer gel run and/or the use of a different nickase in many cases. The method is simple and rapid although for the sample chosen for this study (the GFP gene) the results were compromised by the presence of residual dsDNA and close migration rates of the desired and the larger of the two undesired ssDNA fragments.

\subsection{Asymmetric PCR (aPCR)}

aPCR was carried out using the forward and reverse primers used in standard PCR but at asymmetric ratios. Electrophoretic analysis of the aPCR reaction revealed that large quantities of both dsDNA and ssDNA were created by this method (Figure 2d). Unfortunately, aPCR conditions for all potential substrates must be carefully optimized and, in some cases, ideal conditions may not be obtainable. Further, ssDNA produced by this method must be efficiently separated and isolated from agarose gels and this can also be problematic with common commercial DNA isolation systems (i.e., yields can be unacceptably low).

\section{Discussion}

In this report, we discuss four relatively simple, economical, and scalable methods for obtaining ssDNA for DNA origami and related. Each approach has virtues and liabilities, which are summarized in Table 2. These data corroborate methods described in previous reports and reviews, and adds to them modifications and suggestions to allow 
optimization of the method selected and implemented for any particular purpose. Thus, the following section discusses alternatives and modifications that may be employed as needed to facilitate the use of one or more of the four methods described herein.

Table 2. Benefits and limitations of methods of making ssDNA and available adjustments for enhancing the results.

\begin{tabular}{|c|c|c|c|}
\hline Methods & Benefits & Limitations & Improvements \\
\hline RCA & $\begin{array}{l}\text { - } \text { Isothermal reaction } \\
\text { Large production in } \\
\text { simple overnight } \\
\text { reaction }\end{array}$ & $\begin{array}{l}\text { - } \text { Long reaction time } \\
\text { - } \text { Requires a circular template } \\
\text { - } \text { Requires SSB for ssDNA production } \\
\text { - } \text { removal of excess SSB } \\
\text { Post processing required for } \\
\text { cleaving concatemeric ssDNA } \\
\text { products into monomers }\end{array}$ & $\begin{array}{l}\text { - NRCA with adjusted enzyme } \\
\text { concentrations to get single nick every } \\
\text { replication cycle } \\
\text { - SDA for production of unit length } \\
\text { ssDNA products } \\
\text { - HRCA to make large quantity dsDNA } \\
\text { for subsequent ssDNA production by } \\
\text { chemical denaturation }\end{array}$ \\
\hline $\begin{array}{l}\text { Strand-Specific } \\
\text { Exonuclease }\end{array}$ & $\begin{array}{l}\text { - Simple and rapid } \\
\text { - Selective degradation } \\
\text { of } 5^{\prime} \text { phosphorylated } \\
\text { strand }\end{array}$ & $\begin{array}{l}\text { - Low yield } \\
\text { - Incomplete degradation } \\
\text { - Fractional degradation of desired } \\
\text { strand }\end{array}$ & $\begin{array}{l}\text { - Base modifications to protect the } \\
\text { desired strand } \\
\text { - Use of alternative enzyme such as T7 } \\
\text { exonuclease }\end{array}$ \\
\hline $\begin{array}{l}\text { Chemical } \\
\text { Denaturation }\end{array}$ & $\begin{array}{l}\text { - Simple and rapid } \\
\text { - Optimization not } \\
\text { needed }\end{array}$ & $\begin{array}{l}\text { - Low yield } \\
\text { - Dependent on the location of } \\
\text { nicking site }\end{array}$ & $\begin{array}{l}\text { - Use of biotin-streptavidin induced } \\
\text { mobility shift } \\
\text { - MeR Ry-PCR mediated alkaline } \\
\text { separation }\end{array}$ \\
\hline aPCR & $\begin{array}{l}\text { - } \text { Simple } \\
\text { Large ssDNA } \\
\text { production }\end{array}$ & $\begin{array}{l}\text { - Can require extensive optimization } \\
\text { - Limited amplification cycles due to } \\
\text { formation of byproducts }\end{array}$ & $\begin{array}{l}\text { - Use of } 3^{\prime} \text { terminal modified primers to } \\
\text { block product dimerization } \\
\text { - Optimized polymerase selection } \\
\text { - Optimize primer design } \\
\text { - Emulsion aPCR }\end{array}$ \\
\hline
\end{tabular}

NRCA: Nicking-enhanced Rolling Circle Amplification; SDA: Strand Displacement Amplification; HRCA: Hyperbranched Rolling Circle Amplification.

\subsection{Rolling Circle Amplification (RCA)}

Several approaches can simplify the process of preparing a circular DNA template for RCA. For example, "padlock probe ligation" creates a cyclized ssDNA template by ligation-mediated employing primers that bind to each end of the template [34-37]. Alternative cyclization methods include an enzyme-free chemical reaction between modified bases [38] and primer-free ssDNA cyclization by CircLigase [39]. Once a concatemeric ssDNA product is obtained it may be efficiently reduced to single-length products via either an engineered restriction site hairpin loop $[16,17]$ or a zinc-dependent self-hydrolyzing deoxyribozyme [39]. As a potential workaround of the requirement of SSB and post-reaction cleavage in the method, nicking-enhanced rolling circle amplification (NRCA) can be employed, in which RCA is performed concurrently with nicking reaction. Such concurrent nicking and polymerization can, if optimized, lead to discontinuous progression of RCA, i.e., termination and re-initiation of RCA once every cycle, resulting in accumulation of unit length ssDNA [37]. However, NRCA is difficult to optimize and frequently results in the accumulation of polymerase on a single circular template, resulting in the protrusion of multiple concatemers from a single template $[34,35]$. As an alternative to NRCA for the production of unit-length ssDNA products, concurrent nicking and polymerization can be performed on the linear template, a process termed strand displacement amplification (SDA). Each round of replication is terminated once the polymerase reaches the end of the template, resulting in an equivalent ratio of nicking and polymerization [40]. One limitation of RCA is the time required for the production of large quantities of DNA $[34,35]$. An alternative approach to mitigate this limitation is to use RCA to generate large quantities of dsDNA that may be converted to ssDNA by one of the other methods described herein. 
For example, Hyperbranched Rolling Circle Amplification (HRCA) uses a set of primers in a conventional RCA reaction to make large quantities of concatemeric dsDNA as they "branch out" from a single circular template [41]. Concatemeric dsDNA products can be treated with chemical denaturants such as formamide to generate large quantities of ssDNA if the products can be resolved by AGE.

\subsection{Strand-Specific Lambda Exonuclease Degradation}

A variety of $5^{\prime}$ terminus modifications may be employed for strand-selective Lambda exonuclease ssDNA preparation (e.g., biotin or fluorescent moieties) [21]. However, consideration must be given to the choice of modifier in relation to downstream applications of the resultant products. An attractive variation is to use T7 exonuclease and mitigate its lack of selectivity by introducing phosphorothioate linkages to facilitate efficient strand-specific degradation [21,23].

\subsection{Chemical Denaturation}

The efficiency of the chemical denaturation method is largely dependent on the availability and location of a nickase susceptible site on one strand to ensure adequate separation by AGE. In the absence of a useful nicking site, alternative strategies can be exploited to create a mobility shift in some cases. For example, $5^{\prime}$ biotin-streptavidin modification can result in a substantial electrophoretic mobility shift [27]. A more complex approach developed by Minev et al. entitled Methanol Responsive Polymer RCA (MeR Ry-PCR) circumvents the use of AGE altogether. In the method, undesired strands are tagged with polyacrylamide-co-acrylate through copolymerizing acrylamide and sodium acrylate to the $5^{\prime}$ acrylate-modified primer. Alkaline treatment separates two strands and applying methanol and centrifugal force separates strands into two layers, one of which contains the desired, albeit modified ssDNA [42].

\subsection{Asymmetric PCR (aPCR)}

As mentioned earlier, despite clear advantages, aPCR is hindered by a requirement for substrate-specific optimization for optimal performance and yield. Several steps can be taken to minimize this issue. The choice of polymerase is one key variable. For example, it has been reported that AccuStart HiFi Taq, AccuStart II Taq (Quantabio (Beverly, MA, USA), and LongAmp Taq (NEB) are good choices for aPCR [32]. Further, designing primers whose melting temperatures include consideration of their concentrations as well as GC content can improve yields by reducing the off-target ratio [43]. Performance of aPCR may be further enhanced by a method described by Tolnai et al. wherein $3^{\prime}$ phosphorylated primers ("blockers") are added to standard aPCR mixtures to minimize byproduct formation and thereby increase production yield [33]. Finally, performing aPCR in an emulsion state (a mixture of the aqueous reaction and oil) isolates DNA molecules from each other, mimicking single-molecule aPCR, and thereby reducing the formation of byproducts and increasing yield [44]. Finally, the dsDNA generated during the initial amplification cycles of aPCR can be used as a template for further ssDNA generation by aPCR, strand-specific exonuclease digestion, or chemical denaturation.

\section{Conclusions}

Four ssDNA production methods are described along with their virtues and liabilities (Table 2). RCA provides an efficient method for ssDNA production. However, the dependence on SSB comes at an additional cost. Also, a requirement of a circular template for replication and cleavage of concatemeric products makes overall progress laborious. Lambda exonuclease degradation provides a simple method for ssDNA production, but intrinsic problems of lambda exonucleases result in incomplete degradation and degradation of desired product which affect yield negatively. Formamide separation is a simple alternative for lambda exonuclease degradation, but the method is limited because the nicking site should be located in a favorable way for efficient isolation of the desired strand. 
aPCR is a simple and efficient ssDNA production method. However, the requirement of careful optimizations often holds back the utilization of the method. As DNA nanoengineering continues to mature, these and emergent methods will be critical for the large-scale production of DNA nanosystems.

Supplementary Materials: The following are available online at https:/ / www.mdpi.com/article/ 10.3390/dna2010005/s1, Figure S1: AGE result of standard PCR. M: marker; C: pEGFP-N1; S: standard PCR product, Figure S2: AGE result of ssGFP from strand-specific lambda exonuclease degradation (ssGFP-LE) verification through digestion and SSB treatment. M: marker, C: ssGFP-LE; S1: ssGFP-LE digested with MluI; S2: ssGFP-LE treated with SSB, Figure S3: AGE result of ssGFP from chemical denaturation (ssGFP-F) verification through digestion and SSB treatment. M: marker; C: ssGFP-F; S1: ssGFP-F digested with MluI; S2: ssGFP-F treated with SSB, Figure S4: AGE result of ssGFP from aPCR (ssGFP-A) verification through digestion and SSB treatment. M: marker; C: ssGFP-A; S1: ssGFP-A digested with MluI; S2: ssGFP-A treated with SSB.

Author Contributions: Conceptualization, C.-Y.O. and E.R.H.; methodology, C.-Y.O. and E.R.H.; validation, C.-Y.O. and E.R.H.; formal analysis, C.-Y.O. and E.R.H.; investigation, C.-Y.O. and E.R.H.; resources, E.R.H.; data curation, C.-Y.O.; writing-original draft preparation, C.-Y.O. and E.R.H.; writing-review and editing, C.-Y.O. and E.R.H.; supervision, E.R.H.; project administration, E.R.H. funding acquisition, E.R.H. All authors have read and agreed to the published version of the manuscript.

Funding: Iowa State University President's Interdisciplinary Research Seed Grant (PIRS).

Institutional Review Board Statement: Not applicable. This study did not involve humans or animals.

Informed Consent Statement: Not applicable.

Data Availability Statement: Not applicable.

Conflicts of Interest: The authors declare no conflict of interest. The funders had no role in the design of the study, in the collection, analyses, or interpretation of data; in the writing of the manuscript, or in the decision to publish the results.

\section{References}

1. Ramakrishnan, S.; Ijäs, H.; Linko, V.; Keller, A. Structural stability of DNA origami nanostructures under application-specific conditions. Comput. Struct. Biotechnol. J. 2018, 16, 342-349. [CrossRef] [PubMed]

2. Roodhuizen, J.A.L.; Hendrikx, P.J.T.M.; Hilbers, P.A.J.; de Greef, T.F.A.; Markvoort, A.J. Counterion-Dependent Mechanisms of DNA Origami Nanostructure Stabilization Revealed by Atomistic Molecular Simulation. ACS Nano 2019, 13, 10798-10809. [CrossRef] [PubMed]

3. Dey, S.; Fan, C.; Gothelf, K.; Li, J.; Lin, C.; Liu, L.; Liu, N.; Nijenhuis, M.; Saccà, B.; Simmel, F.; et al. DNA origami. Nat. Rev. Methods Primers 2021, 1, 13. [CrossRef]

4. Rothermund, P. Folding DNA to create nanoscale shapes and patterns. Nature 2006, 440, 297-302. [CrossRef] [PubMed]

5. Chi, Q.; Yang, Z.; Xu, K.; Wang, C.; Liang, H. DNA Nanostructure as an Efficient Drug Delivery Platform for Immunotherapy. Front. Pharmacol. 2020, 10, 1585. [CrossRef]

6. Chandrasekaran, A.R. Nuclease resistance of DNA nanostructures. Nat. Rev. Chem. 2021, 5, 225-239. [CrossRef] [PubMed]

7. Lu, X.; Liu, J.; Wu, X.; Ding, B. Multifunctional DNA Origami Nanoplatforms for Drug Delivery. Chem. Asian J. 2019, 14, $2193-2202$. [CrossRef]

8. Udomprasert, A.; Kangsamaksin, T. DNA origami applications in cancer therapy. Cancer Sci. 2017, 108, 1535-1543. [CrossRef]

9. Choi, Y.; Schmidt, C.; Tinnefeld, P.; Bald, I.; Rödiger, S. A new reporter design based on DNA origami nanostructures for quantification of short oligonucleotides using microbeads. Sci. Rep. 2019, 9, 4769. [CrossRef]

10. Chandrasekaran, A.R.; Punnoose, J.A.; Zhou, L.; Dey, P.; Dey, B.K.; Halvorsen, K. DNA nanotechnology approaches for microRNA detection and diagnosis. Nucleic Acids Res. 2019, 47, 10489-10505. [CrossRef]

11. Bush, J.; Singh, S.; Vargas, M.; Oktay, E.; Hu, C.-H.; Veneziano, R. Synthesis of DNA Origami Scaffolds: Current and Emerging Strategies. Molecules 2020, 25, 3386. [CrossRef] [PubMed]

12. Shepherd, T.R.; Du, R.R.; Huang, H.; Wamhoff, E.-C.; Bathe, M. Bioproduction of pure, kilobase-scale single-stranded DNA. Sci. Rep. 2019, 9, 6121. [CrossRef] [PubMed]

13. Engelhardt, F.A.S.; Praetorius, F.; Wachauf, C.H.; Brüggenthies, G.; Kohler, F.; Kick, B.; Kadletz, K.L.; Pham, P.N.; Behler, K.L.; Gerling, T.; et al. Custom-Size, Functional, and Durable DNA Origami with Design-Specific Scaffolds. ACS Nano 2019, 13, 5015-5027. [CrossRef] 
14. Zhao, W.; Ali, M.M.; Brook, M.A.; Li, Y. Rolling Circle Amplification: Applications in Nanotechnology and Biodetection with Functional Nucleic Acids. Angew. Chem. Int. Ed. 2008, 47, 6330-6337. [CrossRef]

15. Gu, L.; Yan, W.; Liu, L.; Wang, S.; Zhang, X.; Lyu, M. Research Progress on Rolling Circle Amplification (RCA)-Based Biomedical Sensing. Pharmaceuticals 2018, 11, 35. [CrossRef] [PubMed]

16. Ducani, C.; Kaul, C.; Moche, M.; Shih, W.M.; Högberg, B. Enzymatic production of 'monoclonal stoichiometric' single-stranded DNA oligonucleotides. Nat. Methods 2013, 10, 647-652. [CrossRef] [PubMed]

17. Ducani, C.; Bernardinelli, G.; Högberg, B. Rolling circle replication requires single-stranded DNA binding protein to avoid termination and production of double-stranded DNA. Nucleic Acids Res. 2014, 42, 10596-10604. [CrossRef]

18. Van Emmerik, C.L.; Gachulincova, I.; Lobbia, V.R.; Daniëls, M.A.; Heus, H.A.; Soufi, A.; Nelissen, F.H.; van Ingen, H. Ramified rolling circle amplification for synthesis of nucleosomal DNA sequences. Anal. Biochem. 2019, 588, 113469. [CrossRef]

19. Joffroy, B.; Uca, Y.; Prešern, D.; Doye, J.; Schmidt, T.L. Rolling circle amplification shows a sinusoidal template length-dependent amplification bias. Nucleic Acids Res. 2017, 46, 538-545. [CrossRef]

20. Lim, B.; Choong, Y.; Ismail, A.; Glökler, J.; Konthur, Z.; Lim, T. Directed evolution of nucleotide-based libraries using lambda exonuclease. BioTechniques 2012, 53, 357-364. [CrossRef]

21. Murgha, Y.; Rouillard, J.-M.; Gulari, E. Methods for the Preparation of Large Quantities of Complex Single-Stranded Oligonucleotide Libraries. PLoS ONE 2014, 9, e94752. [CrossRef] [PubMed]

22. Citartan, M.; Tang, T.-H.; Tan, S.-C.; Gopinath, S.C.B. Conditions optimized for the preparation of single-stranded DNA (ssDNA) employing lambda exonuclease digestion in generating DNA aptamer. World J. Microbiol. Biotechnol. 2010, 27, 1167-1173. [CrossRef]

23. Lohman, G. The Effect of Nucleic Acid Modifications on Digestion by DNA Exonucleases. New England Biolabs. Available online: https:/ / international.neb.com/tools-and-resources/feature-articles/the-effect-of-nucleic-acid-modifications-on-digestionby-dna-exonucleases (accessed on 20 May 2021).

24. Han, D.; Qi, X.; Myhrvold, C.; Wang, B.; Dai, M.; Jiang, S.; Bates, M.; Liu, Y.; An, B.; Zhang, F.; et al. Single-stranded DNA and RNA origami. Science 2017, 358. [CrossRef] [PubMed]

25. Högberg, B.; Liedl, T.; Shih, W.M. Folding DNA Origami from a Double-Stranded Source of Scaffold. J. Am. Chem. Soc. 2009, 131, 9154-9155. [CrossRef] [PubMed]

26. Avci-Adali, M.; Paul, A.; Wilhelm, N.; Ziemer, G.; Wendel, H. Upgrading SELEX Technology by Using Lambda Exonuclease Di-gestion for Single-Stranded DNA Generation. Molecules 2010, 15, 1-11. [CrossRef] [PubMed]

27. Pagratis, N. Rapid preparation of single stranded DNA from PCR products by streptavidin induced electrophoretic mobility shift. Nucleic Acids Res. 1996, 24, 3645-3646. [CrossRef]

28. Hegedüs, É.; Kókai, E.; Kotlyar, A.; Dombrádi, V.; Szabó, G. Separation of 1-23-kb complementary DNA strands by urea-agarose gel electrophoresis. Nucleic Acids Res. 2009, 37, e112. [CrossRef]

29. Wang, X.; Lim, H.J.; Son, A. Characterization of denaturation and renaturation of DNA for DNA hybridization. Environ. Health Toxicol. 2014, 29, e2014007. [CrossRef]

30. Kilili, G.K.; Tilton, L.; Karbiwnyk, C.M. NaOH concentration and streptavidin bead type are key factors for optimal DNA aptamer strand separation and isolation. BioTechniques 2016, 61, 114-116. [CrossRef]

31. Kuo, T.-C. Streamlined method for purifying single-stranded DNA from PCR products for frequent or high-throughput needs. BioTechniques 2005, 38, 700-702. [CrossRef]

32. Veneziano, R.; Shepherd, T.R.; Ratanalert, S.; Bellou, L.; Tao, C.; Bathe, M. In vitro synthesis of gene-length single-stranded DNA Sci. Rep. 2018, 8, 6548. [CrossRef]

33. Tolnai, Z.; Harkai, Á.; Szeitner, Z.; Scholz, É.N.; Percze, K.; Gyurkovics, A.; Mészáros, T. A simple modification increases specificity and efficiency of asymmetric PCR. Anal. Chim. Acta 2018, 1047, 225-230. [CrossRef] [PubMed]

34. Tian, B.; Fock, J.; Minero, G.A.S.; Garbarino, F.; Hansen, M.F. Ultrasensitive Real-Time Rolling Circle Amplification Detection Enhanced by Nicking-Induced Tandem-Acting Polymerases. Anal. Chem. 2019, 91, 10102-10109. [CrossRef] [PubMed]

35. Tian, B.; Gao, F.; Fock, J.; Dufva, M.; Hansen, M. Homogeneous circle-to-circle amplification for real-time optomagnetic detection of SARS-CoV-2 RdRp coding sequence. Biosens. Bioelectron. 2020, 165, 112356. [CrossRef] [PubMed]

36. Li, X.-H.; Zhang, X.-L.; Wu, J.; Lin, N.; Sun, W.-M.; Chen, M.; Ou, Q.-S.; Lin, Z.-Y. Hyperbranched rolling circle amplification (HRCA)-based fluorescence biosensor for ultrasensitive and specific detection of single-nucleotide polymorphism genotyping associated with the therapy of chronic hepatitis B virus infection. Talanta 2018, 191, 277-282. [CrossRef]

37. Gao, Z.; Wu, C.; Lv, S.; Wang, C.; Zhang, N.; Xiao, S.; Han, Y.; Xu, H.; Zhang, Y.; Li, F.; et al. Nicking-enhanced rolling circle amplification for sensitive fluorescent detection of cancer-related microRNAs. Anal. Bioanal. Chem. 2018, 410, 6819-6826. [CrossRef]

38. Chen, J.; Baker, Y.R.; Brown, A.; El-Sagheer, A.H.; Brown, T. Enzyme-free synthesis of cyclic single-stranded DNA constructs containing a single triazole, amide or phosphoramidate backbone linkage and their use as templates for rolling circle amplification and nanoflower formation. Chem. Sci. 2018, 9, 8110-8120. [CrossRef]

39. Gu, H.; Breaker, R.R. Production of single-stranded DNAs by self-cleavage of rolling-circle amplification products. BioTechniques 2013, 54, 337-343. [CrossRef]

40. Tian, B.; Fock, J.; Minero, G.; Hansen, M. Nicking-associated on-loop and off-loop enzymatic cascade amplification for optomagnetic detection of a highly conserved dengue virus sequence. Biosens. Bioelectron. 2020, 160, 112219. [CrossRef] 
41. Zhu, X.; Feng, C.; Zhang, B.; Tong, H.; Gao, T.; Li, G. A netlike rolling circle nucleic acid amplification technique. Analyst 2014 140, 74-78. [CrossRef]

42. Minev, D.; Guerra, R.; Kishi, J.Y.; Smith, C.; Krieg, E.; Said, K.; Hornick, A.; Sasaki, H.M.; Filsinger, G.; Beliveau, B.J.; et al. Rapid in vitro production of single-stranded DNA. Nucleic Acids Res. 2019, 47, 11956-11962. [CrossRef] [PubMed]

43. Sanchez, J.; Pierce, K.; Rice, J.; Wangh, L. Linear-After-The-Exponential (LATE)-PCR: An advanced method of asymmetric PCR and its uses in quantitative real-time analysis. Proc. Natl. Acad. Sci. USA 2004, 101, 1933-1938. [CrossRef] [PubMed]

44. Shao, K.; Shi, X.; Zhu, X.; Cui, L.; Shao, Q.; Ma, D. Construction and optimization of an efficient amplification method of a random ssDNA library by asymmetric emulsion PCR. Biotechnol. Appl. Biochem. 2015, 64, 239-243. [CrossRef] [PubMed] 